\title{
Preparation of 5-fluorouracil-loaded Nanoparticles and Study of Interaction with Gastric Cancer Cells
}

\author{
Yu-Ling Fan ${ }^{1 *}$, Bing-Yu Fan², Qiang Li ${ }^{3}$ Hai-Xiao Di ${ }^{1}$, Xiang-Yu Meng ${ }^{1}$, Na Ling $^{1}$
}

\begin{abstract}
Aims: To prepare 5-fluorouracil (5-Fu) nanoparticles with higher encapsulation efficiency and drug loading, and then investigate interaction with the SGC-7901 gastric cancer cell line. Materials and Methods: Prescription was optimized by orthogonal experiments, the encapsulation efficiency and loading capacity were tested by highperformance liquid chromatography, and inhibition of proliferation by 5-Fu nanoparticles and 5-Fu given to cells for 24, 48 and 72 hours was investigated by methyl thiazolyl tetrazolium assay (MTT). In addition, 5-Fu nanoparticles were labeled by fluorescein isothiocyanate (FITC), and absorption into cells was tested by flow cytometry. Results: The optimal conditions for preparation were concentrations of $5-\mathrm{Fu}$ of $5 \mathrm{mg} / \mathrm{ml}$, of $\mathrm{CaCl}_{2}$ of $60 \mathrm{mg} / \mathrm{ml}$ and of chitosan of $2 \mathrm{mg} / \mathrm{ml}$. With a stirring speed of 1200rpm, encapsulation efficiency of 5-Fu nanoparticles was $55.4 \pm 1.10 \%$ and loading capacity was $4.22 \pm 0.14 \%$; gastric cancer cells were significantly inhibited by 5-Fu nanoparticles in a time and concentration dependent manner, and compared to 5-Fu with slower drug release, in a certain concentration range, inhibition with 5-Fu nanoparticles was stronger. 5-Fu nanoparticles were absorbed by the cells in line with the concentration. Conclusions: 5-Fu nanoparticles can inhibit growth of gastric cancer cells in vitro to a greater extent than with 5-Fu with good adsorption characteristics, supporting feasibility as a carrier.
\end{abstract}

Keywords: Gastric cancer cells - 5-fluorouracil - nanoparticles - inhibition of proliferation

Asian Pac J Cancer Prev, 15 (18), 7611-7615

\section{Introduction}

5-Fluorouracil ( $5-\mathrm{Fu}$ ) has a broad spectrum of activity against solid tumors, especially has a better therapeutic effect on gastrointestinal cancer (Lorca et al., 2005; Yin et al., 2013). However, 5-Fu has heavy toxic side effects, little affinity to tumor cells, a short plasma half-life, so it was administered by intravenous infusion (Grem, 2000; Manar et al., 2012; Hala et al., 2014). Nanoparticles is an colloidal dispersion system with diameters ranging from $10-1000 \mathrm{~nm}$ which perpared by natural polymers or synthetic polymers (Tsuda, 2010; Fatemeh et al., 2014; Soodabeh et al., 2014). The drug was enfolded or adsorbed on the surface of carriers, nanoparticles has advances in changing the distribution of drugs in the body and the release rate, increasing bioavailability and the permeability of the membrane (Medinaet et al., 2007; Wang et al., 2009). Recently, in order to reduce 5-Fu associated side effects and improve its therapeutic index by use of incorporation of 5-Fu into particulate carriers (Zhang et al., 2006; Li et al., 2008; Chouhan et al., 2009). We select cationic natural polymer chitosan and anionic sodium alginate as the carriers, prepared 5-Fu nanoparticles use the theory of polyelectrolyte complexation (You et al.,
2006). Encapsulation efficiency as the evaluation index, prescription was optimized by orthogonal experiment, encapsulation efficiency and the drug loading was tested by high-performance liquid chromatography. In order to evaluate the efficacy of the dosage form, inhibition of nanoparticles was investigated by methyl thiazolyl tetrazoliym assay (MTT). And 5-Fu nanoparticles were labled by fluorescein isothiocyanate (FITC) (Huang et al., 2004; Zhang et al., 2008; Arora et al., 2011), the absorption of cells after given labled nanoparticles was tested by flow cytometry, and studied its feasibility as carres.

Recently, there are some researches and reviews about nanoparticles published which have anticancer advantages, especially in the Asian Pacific Journal of Cancer Prevention. Such as Curcumin-loaded nanoparticles are effective to inhibit the growth of human lung cancer with little toxicity to normal tissues (Yin et al., 2013). EGFR antisense encapsulated with PAMAM decreased the level of EGFR mRNA and protein (Najar et al., 2013). Paclitaxel-loaded nanoparticles were associated with increased viability of MCF-7 and B 16F0 cells in comparison to free paclitaxel (Yadav et al., 2014). There are some popular nanoparticle materials for example PLGA, Chitoson, PAMAM dendrimer and so on, in

${ }^{1}$ Harbin Commercial University Life Science and Environmental Science Research Center, ${ }^{2}$ National Ministry of Education Antitumor Natural Medicine Engineering Research Center, ${ }^{3}$ School of Chemistry and Materials Science, Heilongjiang University, Harbin, China *For correspondence: 429776474@qq.com 
which, PLGA are reported very much (Nourazarian, et al., 2012; Mirakabad et al., 2014). Except for organic matter, inorganic materials are also used for nanoparticles, for example, silver nanoparticles, gold nanoparticles, $\mathrm{Fe}_{3} \mathrm{O}_{4}$ magnetic nanoparticles (Selin, et al., 2012; Davaran, et al., 2014; Kassas et al., 2014). Some report suggested that the risk of nanoparticles because the enormous difference in size and surface area (Tsuda et al., 2009; 2010).

\section{Materials and Methods}

5-Fu powders (Shanghai Reagent Factory), chitosan (Guoyao Chemical Reagent Co., Ltd.), sodium alginate (Tianjin Yuanhang Chemicals Co., Ltd.), 1640 medium (Invitrogen corporation), trypsin (Sigma), fetal bovine serum (Zhejiang Tianhang bio Technology Co., Ltd.), MTT (Sigma company), dimethyl sulfoxide (Beijing chemical Plant).

\section{Perparation of 5-Fu nanoparticles and chosen of prescription}

Lecithin, ethyl oleate and ethanol were mixed according to a certain mass ratio, add $5-\mathrm{Fu}$ solution $10 \mathrm{ml}$, and then add the sodium alginate solution $3.5 \mathrm{ml}$, stirred 10 minutes (Tianjin Aotesaiensi instrument Co., Ltd., China), $\mathrm{CaCl}_{2}$ solution $15 \mathrm{ml}$ was dropped under slowly stirring for 20 minutes, then put the liquid into the funnel, after stratification, $1 \%$ chitosan acetic acid solution droped into the lower liquid, stirring for 1 hour, $5-\mathrm{Fu}$ nanoparticles get by freeze drying. Encapsulation efficiency as the evaluation index to study the four factors including concentration of 5-Fu, concentration of $\mathrm{CaCl}_{2}$, concentration of chitosan and stirring speed to further optimize the prescription prescription by orthogonal experiment.

\section{Characterization of nanoparticles}

The shape of 5-Fu nanoparticles was observed by a transmission electron microscope (TEM, H-7650 Hitachi Co., Japan). Take $0.3 \mathrm{~g}$ powder of nanoparticles dispersed in $1 \mathrm{ml}$ solution, one drop of 5-Fu nanoparticles was added to a copper supported mesh membrane and the excess solution removed with filter paper. Then, $1 \%$ phosphotungstic acid was added to the mesh membrane. Excess solution was removed after 5 minutes, the sample dried at room temperature and then examined with the electron microscope. The size and zeta potential of 5-Fu nanoparticles was assessed using a nano-sizer potential analyzer (Zetasizer Nano-ZS90 Malvern Instruments Ltd., UK). The suspension of nanoparticles put in a sample cells, and then put in a measurement cells. The particle size analysis and zeta potential were carried out by nanosizer potential analyzer.

\section{In vitro drug release from nanoparticles}

In vitro $5-\mathrm{Fu}$ release profiles of $5-\mathrm{Fu}$ nanoparticles were determined as follows. Take 50mg 5-Fu nanoparticles powers dispersed in $5.0 \mathrm{~mL}$ phosphate buffer saline (PBS), and placed into a dialysis membrane bag with a molecular weight of $10 \mathrm{kDa}$, tied and placed into $50.0 \mathrm{~mL}$
PBS medium. The entire system was kept at $37^{\circ} \mathrm{C}$ with continuous oscillation frequency. At different times, $3 \mathrm{~mL}$ release medium was removed at each time point and $3 \mathrm{~mL}$ fresh medium PBS solution was added into the system. The amount of 5-Fu in the release medium was evaluated by liquid phase chromatography (HPLC, waters 2695 Co., USA). All measurements were performed in triplicate.

\section{Encapsulation efficiency and loading capacity}

The encapsulation efficiency and loading capacity of nanoparticles were determined by separation of nanoparticles from the aqueous medium containing nonassociated 5-Fu by ultracentrifugation (Allegra 64R Beckman Coulter Inc., USA) at $28000 \mathrm{r} / \mathrm{min}$ for $1 \mathrm{~h}$ at $4{ }^{\circ} \mathrm{C}$. The amount of free 5-Fu in the supernatant was measured by HPLC. HPLC was performed using a The 5-Fu nanoparticles were separated from the aqueous suspension medium through ultracentrifugation. The detective wavelength was set at $265 \mathrm{~nm}$. HPLC analysis of samples was performed using a Kromasil C18 $(4.6 \times 250 \mathrm{~mm}, 5 \mu \mathrm{m}$, China). The column temperature was maintained at $30^{\circ} \mathrm{C}$. The mobile phase was a mixture of methanol/water (5:95). The flow rate was $0.8 \mathrm{~mL} / \mathrm{min}$. The $5-\mathrm{Fu}$ encapsulation efficiency (EE) and the 5-Fu loading capacity (LC) of nanoparticles were calculated as follows:

$E F=[$ (The amount of 5-Fu - free 5-Fu $) \div$ The amount of $5-\mathrm{Fu}] \times 100 \%$

$L C=[($ The amount of $5-\mathrm{Fu}-$ free $5-\mathrm{Fu}) \div$ Total amount of nanoparticles weight $] \times 100 \%$

\section{Iinhibition effect of 5-FU nanoparticles}

Human gastric cancer cell line SGC-7901 were incubated in 1640 medium at $37^{\circ} \mathrm{C}, 5 \% \mathrm{CO}_{2}$ incubator, with $10 \%$ fetal bovine serum (FBS) and $100 \mathrm{U} / \mathrm{mL}$ penicillin-streptomycin. SGC-7901 cells at logarithmic growth phase $\left(3 \times 10^{4}\right.$ cells $\left./ \mathrm{mL}\right)$ were added to 96 -well culture plates $(100 \mu \mathrm{L} /$ well $)$, and then incubated $24 \mathrm{~h}$. Then different concentrations of blank nanoparticles, 5-Fu nanoparticles and 5-Fu were added into the wells $(100 \mu \mathrm{l} /$ well). Concentration of drugs were $1,3,10,30$, $100 \mu \mathrm{g} / \mathrm{ml}$, and the control group was not administered, each group with six parallel wells, placed in $37^{\circ} \mathrm{C}, 5 \%$ $\mathrm{CO}_{2}$ incubator until the scheduled time. Then $20 \mu \mathrm{L}$ MTT solution $(0.5 \mathrm{mg} / \mathrm{mL}$ in PBS, $\mathrm{pH} 7.4)$ was added to cells (100 $\mu \mathrm{L} /$ well), followed by further incubation for 4 hours. Thereafter, the media was removed and added dimethyl sulfoxide (DMSO) $(150 \mu \mathrm{L} /$ well), mixed by low speed oscillation. The absorbance (OD) was read at $570 \mathrm{~nm}$ on microplate reader (Model 680 Bio-rad Co., USA). The inhibition rate was calculated as follows:

Inhibition rate $(\%)=[1-($ Administered group $O D \div$ Control group OD) $] \times 100 \%$

\section{Preparation of FITC-labeled nanoparticles}

The synthesis of FITC-labeled nanoparticles was based on the reaction between the isothiocyanate group of FITC and the amino group of chitosan. Nanoparticles $(0.1 \mathrm{~g})$ dispersed in aqueous solution, the concentration of nanoparticles is $1 \mathrm{~g} / \mathrm{L}$, then added $10 \mathrm{~g} / \mathrm{LDMSO}$ solution of FITC, volume ratio of nanoparticle dispersions and DMSO is $3 \mathrm{ml}$ : $0.3 \mathrm{ml}$. Reaction in dark for 3 hours, then get FITC- 
conjugated fluorescent nanoparticles after centrifugation and washing, keep it from light.

\section{Cells uptake of FITC-labeled nanoparticles}

SGC-7901 cells at logarithmic growth phase $\left(20 \times 10^{4}\right.$ cells $/ \mathrm{mL})$ were added to 6 -well culture plates $(1 \mathrm{~mL} /$ well $)$, and then incubated $24 \mathrm{~h}$. then different concentrations of FITC-labeled nanoparticles were added into the wells (1ml/well). Concentration of nanoparticles were 10, 30, $100 \mu \mathrm{g} / \mathrm{ml}$, and the control group was given free FITC, each group with three parallel wells, placed in $37^{\circ} \mathrm{C}, 5 \%$ $\mathrm{CO}_{2}$ incubator for $24 \mathrm{~h}$. Then wash the cells with PBS for three times to remove the free drugs, the fluorescence intensity measured by flow cytometry.

\section{Statistical analysis}

All data were presented as mean \pm standard deviation $(\overline{\boldsymbol{x}} \pm s)$, spss statistics as the data analyse software.

\section{Results and Discussion}

\section{The results of orthogonal experiment}

Encapsulation efficiency as the evaluation index to study the four factors including concentration of $5-\mathrm{Fu}$, concentration of $\mathrm{CaCl}_{2}$, concentration of chitosan and stirring speed (Table 1 ). The results of $\mathrm{L}_{9}\left(3^{4}\right)$ orthogonal experiment were shown in Table 2. As it is shown in Table 2, the degree of the factors affect encapsulation efficiency is $\mathrm{B}>\mathrm{C}>\mathrm{D}>\mathrm{A}$. The optimal reaction conditions is $A_{1} B_{2} C_{2} D_{2}$, that is, the concentration of $5-F u$ is $5 \mathrm{mg} / \mathrm{ml}$, the concentration of $\mathrm{CaCl}_{2} 60 \mathrm{mg} / \mathrm{ml}$, the concentration of chitosan is $2 \mathrm{mg} / \mathrm{ml}$, stirring speed is $1200 \mathrm{rpm}$.

\section{Characterization of nanoparticles}

TEM images shown in Figure 1 reveal that the morphology of nanoparticles are spherical shape, The actual diameter of the nanoparticles observed by TEM

\section{Table 1. Factors and Level}

\begin{tabular}{lcccc}
\hline Level & \multicolumn{4}{c}{ Factors } \\
& $\begin{array}{c}\mathrm{A} 5-\mathrm{Fu} \\
\left(\mathrm{mg} \cdot \mathrm{ml}^{-1}\right)\end{array}$ & $\begin{array}{c}\mathrm{B} \mathrm{CaCl}_{2} \\
\left(\mathrm{mg} \cdot \mathrm{ml}^{-1}\right)\end{array}$ & $\begin{array}{c}\mathrm{C} \text { chitosan } \\
\left(\mathrm{mg} \cdot \mathrm{ml}^{-1}\right)\end{array}$ & $\begin{array}{c}\text { D stir speed } \\
(\mathrm{rpm})\end{array}$ \\
\hline 1 & 5 & 45 & 1.6 & 900 \\
2 & 6 & 60 & 2 & 1200 \\
3 & 7 & 75 & 2.4 & 1500 \\
\hline
\end{tabular}

\section{Table 2. $\mathrm{L}_{9}\left(3^{4}\right)$ Orthogonal Experiment}

\begin{tabular}{lccccl}
\hline Experiment number & \multicolumn{5}{c}{ Factors } \\
& $\mathrm{A}$ & $\mathrm{B}$ & $\mathrm{C}$ & $\mathrm{D}$ & \\
\hline 1 & 1 & 1 & 1 & 1 & 40.4 \\
2 & 1 & 2 & 2 & 2 & 54.22 \\
3 & 1 & 3 & 3 & 3 & 36.72 \\
4 & 2 & 1 & 2 & 3 & 42.52 \\
5 & 2 & 2 & 3 & 1 & 45.3 \\
6 & 2 & 3 & 1 & 2 & 37.32 \\
7 & 3 & 1 & 3 & 2 & 40.83 \\
8 & 3 & 2 & 1 & 3 & 43.7 \\
9 & 3 & 3 & 2 & 1 & 42.27 \\
$\mathrm{~K}_{1}$ & 43.78 & 41.25 & 40.47 & 42.66 & \\
$\mathrm{~K}_{2}$ & 41.71 & 47.74 & 46.34 & 44.12 & \\
$\mathrm{~K}_{3}$ & 42.27 & 38.77 & 40.95 & 40.98 & \\
$\mathrm{R}$ & 2.07 & 8.97 & 5.87 & 3.14 & \\
\hline
\end{tabular}

was approximately $50-200 \mathrm{~nm}$. The average particle size is $215 \mathrm{~nm}$ (Figure 2) which detected by nano-sizer potential analyzer, the polydispersity index PDI is 0.164 . It was reported that large particles hardly reach the cells, while smaller particles tended to accumulate in the tumor sites due to the enhanced permeability and retention (EPR) efftct and a greater internalization was also observed. Zeta potential of nanoparticles is about $0.0534 \mathrm{mV}$.

The size of 5-Fu nanoparticles observed under transmission electron microscope is smaller than the result of nano-sizer potential analyzer detected. May be due to the low zeta potential of nanoparticles, the electrostatic repulsion between particles is small, unstable particles easily reunion, although PDI value is low, it only shows the size distribution of aggregates.

In vitro release, encapsulation efficiency and loading capacity

Nanoparticle release occurs by 2 methods: "burst release" and "sustained release". Burst release is the rapid release of a drug from the surface of nanoparticles or diffusion from the polymer matrix. This allows the drug to rapidly reach an effective concentration in the circulation. Sustained release is the slow release of a drug that is entrapped within nanoparticles during nanoparticle bio-degradation. This allows the drug to stay at an effective concentration in the circulation over time. Figure 3 shows the in vitro 5 -Fu release profiles from nanoparticles in water and PBS ( $\mathrm{pH}=7.4)$, and the release rate in PBS faster
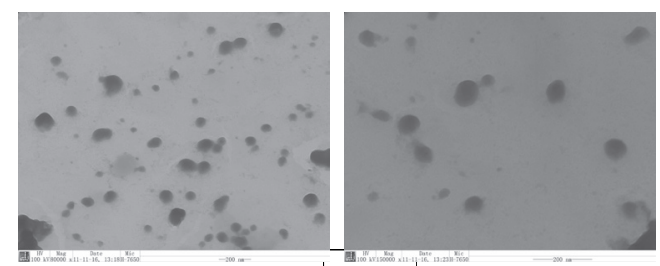

Figure 1. Transmission Electron Micrograph of 5-Fu Nanoparticles

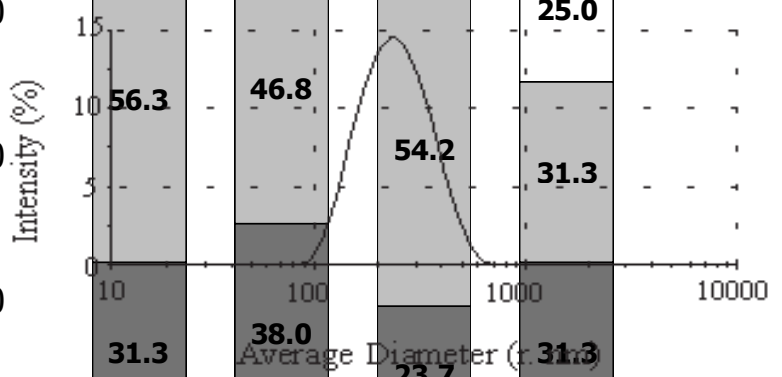

Figure 2. Size Distribution of 5-Fu Nanoparticles

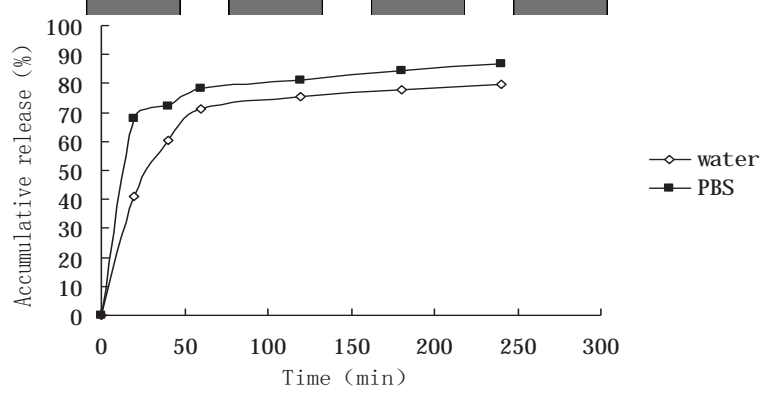

Figure 3. In vitro Release of 5-Fu from Nanoparticles in the Water and PBS 

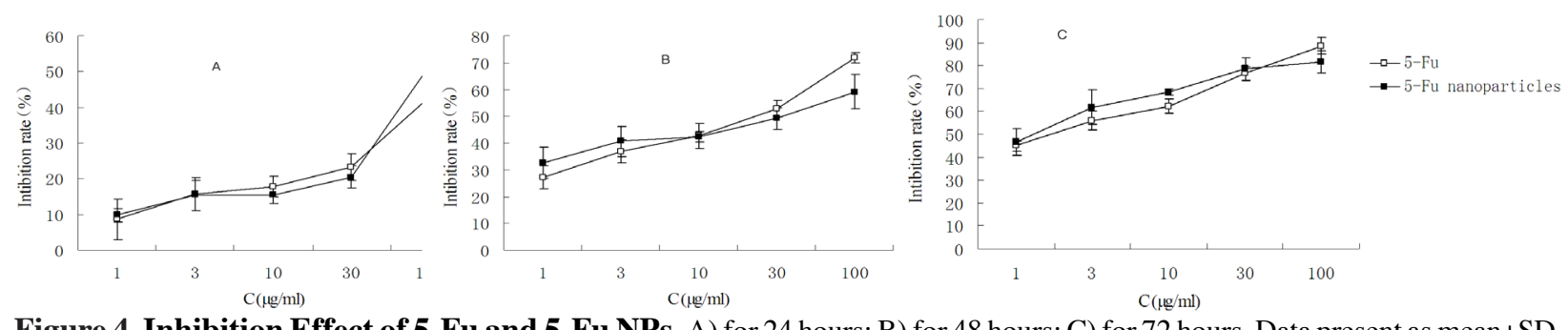

Figure 4. Inhibition Effect of 5-Fu and 5-Fu NPs. A) for 24 hours; B) for 48 hours; C) for 72 hours. Data present as mean \pm SD, $\mathrm{n}=6$. $* \mathrm{P}<0.05$ represent 5 -Fu NPs compared with 5 -Fu

Table 3. OD of Blank Nanoparticles Effect on SGC7901 Cells for Different Times $(\bar{x} \pm s, n=6)$

\begin{tabular}{lccc}
\hline Concentration $(\mu \mathrm{g} / \mathrm{ml})$ & \multicolumn{3}{c}{ OD } \\
& $24 \mathrm{~h}$ & $48 \mathrm{~h}$ & $72 \mathrm{~h}$ \\
\hline Control group & $0.421 \pm 0.058$ & $0.502 \pm 0.067$ & $0.727 \pm 0.053$ \\
1 & $0.431 \pm 0.068$ & $0.518 \pm 0.056$ & $0.736 \pm 0.020$ \\
3 & $0.436 \pm 0.041$ & $0.513 \pm 0.060$ & $0.730 \pm 0.057$ \\
10 & $0.440 \pm 0.052$ & $0.534 \pm 0.045$ & $0.745 \pm 0.061$ \\
30 & $0.433 \pm 0.047$ & $0.556 \pm 0.031$ & $0.773 \pm 0.088$ \\
100 & $0.451 \pm 0.036$ & $0.580 \pm 0.064$ & $0.806 \pm 0.037$ \\
\hline
\end{tabular}

Table 4. The Results of Flow Cytometry

\begin{tabular}{lc}
\hline Concentrationof nanoparticles $(\mu \mathrm{g} / \mathrm{ml})$ & Fluorescence intensity \\
\hline Control group & $26.9 \pm 0.1$ \\
10 & $30.2 \pm 4.1$ \\
30 & $120.8 \pm 3.4$ \\
100 & $293.1 \pm 0.1$ \\
\hline
\end{tabular}

than in water. The 5-Fu release profiles are composed of burst release and sustained release. The burst release, which resulted in the release of $60 \%$ of the 5 -Fu, occurred from 0 to $1 \mathrm{~h}$. The sustained release occurred from 1 to $5 \mathrm{~h}$ and resulted in the release of $60 \%$ of the $5-\mathrm{Fu}$. The encapsulation efficiency (EE) of 5-Fu nanoparticles was $55.36 \pm 1.10 \%$, and the loading capacity was $4.22 \pm 0.14 \%$

In this experiment, we perpared 5-Fu nanoparticles of higher encapsulation efficiency with the natural polymer as the carriers, but loading capacity is low. It might be because of the prescription contains more excipients, but most of them are natural materials, have good safe, so do not affect drug activity. In addition, there are still some shortcomings in detecting the content of samples. In the sample processing, the centrifuge speed is fast, a large centrifugal force may cause drug leakage, resulting in encapsulation efficiency and loading capacity reduce. But this method is simple, it can be used for the determination of nanoparticles in the condersion of minimize the loss of drug,

\section{Iinhibition effect of 5-Fu nanoparticles}

As it is shown in Table 3, different concentrations of blank nanoparticles effect on SGC-7901 cells after 24, 48 and 72 hours, there is no significant difference about OD values compared with the control group $(P>0.05)$. Indicating that drug excipients have no toxic side effects, have good security . However, OD values of each group were higher than control group, indicating that the nanoparticles have an effect on promote cell proliferation (Table 3).

We performed a series MTT assays to compare the inhibition effect of 5-Fu nanoparticles with free
5-Fu. As shown in Figure 4, inhibition effect of 5-Fu and 5-Fu nanoparticles showed time-dependent and concentration-dependent. For 24 hours, inhibition rate of 5 -Fu nanoparticles with concentration of $100 \mu \mathrm{g} / \mathrm{ml}$ was significantly higher than 5 -Fu, inhibition rate of other concentrations of nanoparticles lower or approch to $5-\mathrm{Fu}$. For 48 hours, inhibition rate of 5-Fu nanoparticles with the concentration of $1 \mu \mathrm{g} / \mathrm{ml}$ and $3 \mu \mathrm{g} / \mathrm{ml}$ are higher than $5-\mathrm{Fu}$, and there is the significant differences between 5-Fu nanoparticles and 5-Fu with the concentration of $1 \mu \mathrm{g} / \mathrm{ml}$. But, inhibition rate of 5-Fu nanoparticles with the concentration of $100 \mu \mathrm{g} / \mathrm{ml}$ was significantly lower than 5-Fu. For 72 hours, except for inhibition rate of 5-Fu nanoparticles with the concentration of $100 \mu \mathrm{g} / \mathrm{ml}$ was significantly lower than 5-Fu, inhibition rate of the other concentrations of $5-\mathrm{Fu}$ nanoparticles were higher than the 5-Fu, and there is significant different between 5-Fu nanoparticles and 5-Fu with the concentration of $3 \mu \mathrm{g} /$ $\mathrm{ml}$ and $10 \mu \mathrm{g} / \mathrm{ml}$. These results suggest that, in addition to nanoparticles with the concentration of $100 \mu \mathrm{g} / \mathrm{ml}$, the other concentration of nanoparticles showed the slowly drug release compared to 5-Fu, inhibition rate stronger than 5-Fu along with the time effect on the cells.

MTT assay showed that 5-Fu nanoparticles significantly inhibited the cells, and showed time-dependent and concentration-dependent . However, at 72 hours, in addition to 5 - Fu nanoparticles with the concentration of $100 \mu \mathrm{g} / \mathrm{ml}$, the other concentrations of 5-Fu nanoparticles showed stronger inhibition effect than 5-Fu.It indicating that 5-Fu nanoparticles release drugs slower than 5-Fu in a certain range of concentration. But 5-Fu nanoparticles with the concentration of $100 \mu \mathrm{g} / \mathrm{ml}$ showed stronger inhibition effect than 5-Fu in the early stage, and weaker than 5-Fu along with the time. May be due to the carrier materials have a certain role in promoting proliferation of cells (Table 3), as a result of the impact of carrier materials, the inhibition rate reduce. In addition, the cell uptake of nanoparticles including membrane transport, adsorption and endocytosis, endocytosis is the main way of particle uptake by cells which the particle size less than $500 \mathrm{~nm}$, but the particle size and surface charge are also the main factors affect cell absorption of nanoparticles (Wang et al., 2009; Manar et al., 2012; Soodabeh et al., 2014).

Surface of tumor cells have more negative charge than normal cells, while chitosan can adsorp cells through cationic charge (Zhang et al., 2008), the higher the concentration is, the more electric charge and the stronger the adsorption. Therefore, 5-Fu nanoparticles with the concentration of $100 \mu \mathrm{g} / \mathrm{ml}$ showed strong inhibition in the early phase. 


\section{Cellular uptake of nanoparticles}

As shown in Table 4, nanoparticles can be absorbed by the cells, and dependent on the concentration of nanoparticles, the higher the concentration of nanoparticles, the stronger the fluorescence intensity. It has been reported that cellular uptake studies performed with fluorescent marker molecules had some limitations. In this study, although all uptake experiments were performed carefully and promptly under light protection and the incubation time was 24 hours, the decrease in the measurement could also result from photobleaching of the FITC and not be related to the decrease in uptake rate.

Flow cytometry results showed that the nanoparticles can be absorbed by the cells, indicating that the nanoparticles as a carrier of 5-Fu is feasible. In addition, fluorescent nanoparticles can also be used for tracer experiments (Zhang et al., 2008), and provide the basis for its targeting study. However, we couldn't sure the fluorescent rate of labeled nanoparticles, so can only do qualitative analysis but quantitative analysis. In addition, we need further study of the way and site of the nanoparticles absorb.

In conclusion, in this study we successfully synthesized 5-Fu nanoparticles, which can inhibit growth of gastric cancer cells in vitro, and inhibition of the gastric cancer cells stronger than 5-Fu in a certain concentration range, the nanoparticles can be absorbed by the cells, which provided the feasibility as a carrier of 5-Fu. Therefore, it may be used as a safe and effective novel anti-tumor preparation with profound prospects in clinical application.

\section{References}

Arora S, Gupta S, Narang RK, et al (2011). Amoxicillin loaded chitosan-alginate olyelectrolyte complex nanoparticles as copenetrating delivery system for H. Pylori. Sci Pharm, 79, 673-94.

Champion JA, Walker A, Mitragotri S (2008). Role of particle size in phagocytosis of polymeric microspheres. Pharm Res, 25, 1815-21.

Chung YC, Su YP, Chen CC (2004). Relationship between antibacterial activity of chitosan and surface characteristics of cell wall. Acta Pharmacol Sin, 25, 932-6.

Chouhan R, Bajpai A (2009). An in vitro release study of 5-fluoro-uracil (5-FU) from swellable poly- (2-hydroxyethyl methacrylate) (PHEMA) nanoparticles. J Mater Sci: Mater Med, 20 1103-14.

Fatemeh SMT, Kazem N-K, Abolfazl A, et al (2014). PLGAbased nanoparticles as cancer drug delivery systems. Asian Pac J Cancer Prev, 15, 517-35.

Grem JL (2000). 5-Fluorouracil: forty-plus and still ticking. A review of its preclinical and clinical development. Invest New Drugs, 18, 299-313.

Hala YEK, Azza AA (2014). Bactericidal application and cytotoxic activity of biosynthesized silver nanoparticles with an extract of the red seaweed pterocladiella capillaceaon the HepG2 cell line. Asian Pac J Cancer Prev, 15, 1299-306.

Huang M, Khor E, Lim LY (2004). Uptake and cytotoxicity of chitosan molecules and nanoparticles: effects of molecular weight and degree of deacetylation. Pharma Res, 21, 344-53.

Huang M, Ma ZS, Khor E, et al (2002). Uptake of FITC-chitosan nanoparticles by A549 cells. Pharm Res, 19, 1488-94.

Li S, Wang AX, Jiang WQ, et al (2008). Pharmacokinetic characteristics and anticancer effects of 5-fluorouracil loaded nanoparticles. BMC Cancer, $\mathbf{8}, 103$.

Llorca FC, Esquerdo GG, Cervera GJ, et al (2005). 5-Fluorouracilinduced small bowel toxicity in a patient with colorectal cancer. Clin Transl Oncol, 7, 356-57.

Manar ES, Awatif AH (2012). Gold nanoparticles induce apoptosis in MCF-7 human breast cancer cells. Asian Pac J Cancer Prev, 13, 1617-20.

Medina C, Santos-Martinez MJ, Radomsk A, et al (2007). Nanoparticles: pharmacological and toxicological significance. Bri J Pharmacol, 150, 552-8.

Osaka T, Nakanishi T, Shanmugam S, et al (2009). Effect of surface charge of magnetite nanoparticles on their internalization into breast cancer and umbilical vein endothelial cells. Colloid Surface B, 71, 325-30.

Soodabeh D, Samira A, Kazem N-K, et al (2014). Physicochemical characteristics of $\mathrm{Fe}_{3} \mathrm{O}_{4}$ magnetic nanocomposites based on poly ( $\mathrm{N}$-isopropylacrylamide) for anti-cancer drug delivery. Asian Pac J Cancer Prev, 15, 49-54.

Thorek D, Tsourkas A (2008). Size, charge and concentration dependent uptake of iron oxide particles by non-phagocytic cells. Biomaterials, 29, 3583-90.

Tsuda H (2010). Risk assessment studies of nanomaterials in Japan and other countries. Asian Pac J Cancer Prev, 10, 13-4.

Wang X, Wang YQ, Chen Z, et al (2009). Advances of cancer therapy by nanotechnology. Cancer Res Treat, 41, 1-11.

Yin HT, Zhang DG, Wu XL, et al (2013). In vivo evaluation of curcumin-loaded nanoparticles in a A549 xenograft mice model. Asian Pac J Cancer Prev, 14 409-12.

You J Ch, Liu Y Ch, Peng Ch A (2006). Effcient gene transfection using chitosan-alginate core-shell nanoparticles. Int $J$ Nanomed, 1, 173-80.

Zhang DY, Shen XZ, Wang JY, et al (2008). Preparation of chitosan-polyaspartic acid-5-fuorouracil nanoparticles and its anti-carcinoma effect on tumor growth in nude mice. World J Gastroenterol, 14, 3554-62.

Zhang J, Chen XG, Peng WB, et al (2008). Uptake of oleoylchitosan nanoparticles by A549 cells. Nanomedicine: Nanotechnology Biology Medicine, 4, 208-14.

Zhang Y, Zhuo RX (2006). Synthesis, characterization and in vitro 5-fu release behavior of poly (2, 2-dimethyltrimethylenecarbonate)-poly (ethyleneglycol)poly (2, 2-dimethyltrim-ethylenecarbonate) nanoparticles. J Biomed Materials Res, 76, 674-80. 